\title{
ANALISIS KEKUATAN DIES FRAME LINK PADA MESIN ROLL PIPA 2 IN PENGGERAK HIDROLIK DENGAN METODE ELEMEN HINGGA
}

\author{
Sodiq Kuntoro \\ Program Studi Teknik Mesin, Fakultas Teknik, \\ Universitas Muria Kudus \\ Email:201554145@std.umk.ac.id \\ Masruki Kabib \\ Program Studi Teknik Mesin, Fakultas Teknik, \\ Universitas Muria Kudus \\ Email: masruki.kabib@umk.ac.id
}

\begin{abstract}
ABSTRAK
Mesin roll pipa yang ada di bengkel umum kebanyakan masih manual menggunakan ulir sebagai media penekan pipa. Sistem ini memiliki kekurangan yaitu memerlukan tenaga yang besar dari operator. Dengan memanfaatkan sistem hidrolik akan memperingan dalam pengoperasian mesin roll pipa. Mesin rol pipa dengan penggerak hidrolik ini menggunakan dua dies yang disatukan dengan frame dan ujungnya dihubungkan dengan aktuator hidrolik. Tujuan dari penelitian adalah menganalisa kekuatan dies frame link terhadap gaya pembengkokan pipa sebesar $220 \mathrm{kN}$, menggunakan metode elemen hingga. Metode yang digunakan adalah mendesain dies dan frame, menentukan dimensi dies dan frame, menggambar pada inventor, menganalisa dengan metode lemen hingga. Hasil yang diperoleh setelah di analisa dengan metode elemen hingga menggunakan software adalah aman, bagian dies yang memperoleh pembebanan paling tinggi pada daerah yang bersinggungan dengan pipa. Nilai Tegangan principal, displacement dan tegangan von mises lebih kecil dari hasil analisa perhitungan.
\end{abstract}

Kata kunci: roll pipa; dies frame link; analisa kekuatan; metode elemen hingga.

\section{ABSTRACT}

Pipe roll machines in the general workshop are mostly still manual using a thread as a press of the pipe. This system has a deficiency that requires a large power from the operator. By utilizing hydraulic system will be lightening in the operation of pipe roll machine. Pipe roll machine with hidraulic system is uses two dies that are joined to the frame and the ends are connected to a hydraulic actuator. The purpose of study is to analyze the strength of dies frame link to bending force style of $220 \mathrm{KN}$, using finite element method. The method used is designing dies and frames, determining dimensions of dies and frames, drawing on inventors, analyzing with finite element method. The results obtained after being analized with the finite element method uses software are safe, the part of the dies that obtains the highest load on the area in contact with the pipe. The value of principal stress, displacement and von mises stress less than calculation analysis.

Keywords: pipe roll; dies frame link; strengh analysis; finite element method

\section{PENDAHULUAN}

Pengerolan pipa merupakan proses pembentukan pipa yang banyak dilakukan untuk membuat komponen-komponen industri maupun rumah tangga misalnya membuat kontrruksi, kanopi, pagar, kursi dan komponen lainnya yang menggunakan bahan pipa. Proses pembentukan ini dilakukan dengan memberi beban melampaui kekuatan elastisnya yaitu pada daerah plastis. Studi tentang analisa tegangan di luar batas elastis untuk berbagai material telah banyak dilakukan, baik secara teoritis maupun melalui eksperimen. Proses pembuatan komponen mesin diperlukan perancangan dan analisa terhadap proses pembentukan. Salah satunya mesin roll pipa, bagian utamamya adalah dies. Komponen ini menerima gaya paling besar dibanding komponen lain serta bersinggungan langsung dengan benda kerja (pipa). Dengan kondisi ini perlu perancangan yang baik agar mesin roll pipa tidak mengalami kegagalan seperti dies retak ataupun frame patah atau bengkok.

Proses bending adalah proses perubahan bentuk logam secara plastis lewat roll, penjepit dan pembentuk (die) dimana bentuk yang tadinya lurus menjadi lengkungan. Proses bending dilakukan dengan menekuk benda kerja hingga mengalami perubahan bentuk yang menimbulkan peregangan pada sisi luar benda kerja pada sekitar daerah garis lurus. Proses bending ini tidak hanya berfungsi untuk membentuk 
benda kerja tetapi juga berguna untuk meningkatkan sifat mekanik berupa kekakuan dari suatu benda yang telah mengalami proses bending dengan cara menambah momen inersia bending [1].

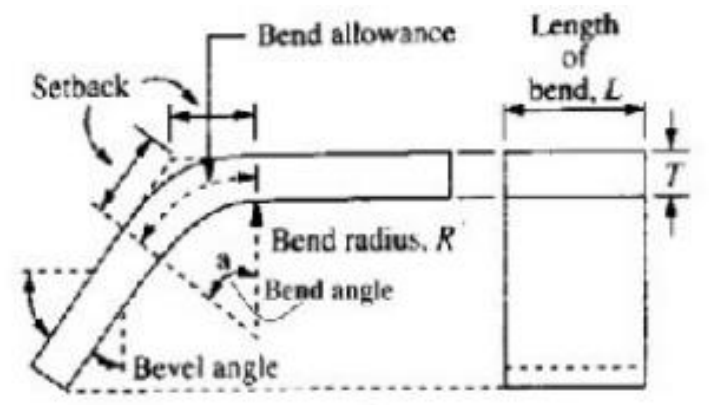

Gambar 1. Pembengkokan Pipa [1]

Pada gambar 1 menunjukkan bahwa pada proses bending tegangan tarik terjadi pada sisi luar dari benda kerja dan tegangan tekan pada sisi dalamnya yang dipisahkan oleh sumbu netral yang diasumsikan berada ditengah-tengah ketebalan pipa atau bentuk plat.. Tegangan tarik yang terlalu besar dapat menyebabkan retak pada sisi luar, dan sebaliknya jika tegangan tarik terlalu terlalu kecil akan menyebabkan kerutan pada bagian dalam benda kerja. Radius bending juga berpengaruh dalam proses bending dimana jika radius terlalu kecil akan dapat menimbulkan regangan tarik yang cukup besar pada sisi luar yang akhirnya dapat menimbulkan retak sedangkan pada bagian dalam akan terjadi kerutan akibat regangan akibat tekanan [1].

Metode pengerolan pipa bervariasi tergantung radius dan material pipa ada metode rotary draw bending, mandrel bending, three roll bending, bending springs, and heat induction. Masalah yang dapat timbul saat pengerolan antara lain: terdapat kerutan pada hasil pembengkokan pipa, oval, penipisan ketebalan pipa akibat deformasi dan spring back [2]. Diatasi dengan mendesain diameter dies besar 5 kali diameter pipa dan diameter dies kecil 3 kali diameter pipa [3]. Proses pengerolan pipa pada pengerjaan dingin juga dapat dilakukan optimasi dengan berbagai metode, salah satunya dengan metode taguchi dan metode elemen hingga [4].

Selama proses pembengkokan pipa berpotensi mengalami keovalan seperti di tunjukkan pada gambar 2, maka perlu adanya penahan. Pipa yang akan dibengkokan ditahan oleh penahan dan dies, anak panah menunjukkan gaya reaksi dari pipa terhadap dies dan penahan seperti ditunjukkan pada gambar 3 . Saat proses banding titik A dan B berpindah mendekat titik tengah diameter sehingga pipa berbentuk oval. Untuk mengatasinya diperlukan penahan pada titik $\mathrm{C}$ dan $\mathrm{D}$ [5].

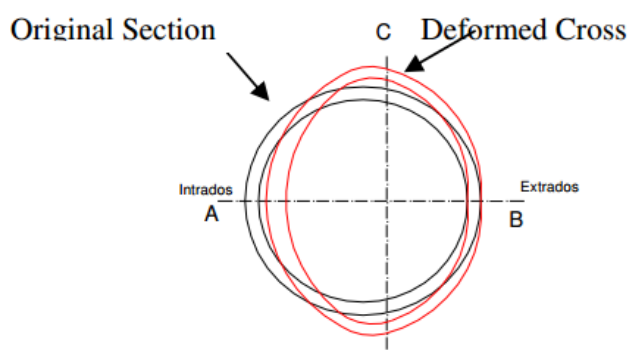

Gambar 2. Perubahan Bentuk Pipa Akibat Pembengkokan [3]

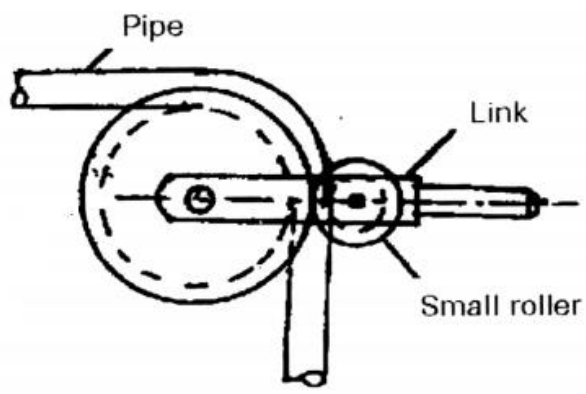

Gambar 3. Pembengkokan Pipa [3]

Pada proses pembenkokan pipa, semakin besar sudut pembengkokan $\theta$ yang digunakan, semakin besar nilai prosentase ovalisasinya. Semakin besar radius dies (R) yang digunakan, semakin kecil nilai prosentase 
ovalisasinya. Pemberian internal pressure mempengaruhi ovalisasi dari pipa, sehingga diameter besar maupun kecil masuk toleransi yang diizinkan yaitu $\pm 10 \%$ untuk pipa kursi lipat [6].

Analisa pembebanan pada frame dilakukan dengan metode elemen hingga mengunakan sofware. Dasar dari metode elemen hingga adalah membagi benda kerja menjadi elemen-elemen kecil yang jumlahnya berhingga sehingga dapat menghitung reaksi akibat beban pada kondisi batas yang diberikan [7]

\section{METODOLOGI PENELITIAN}

Metode yang digunakan dalam penelitian ini adalah mendesain dies dan frame, menentukan dimensi dies dan frame, menggambar pada inventor, menganalisa dengan inventor sebagaimana ditunjukkan gambar 4.

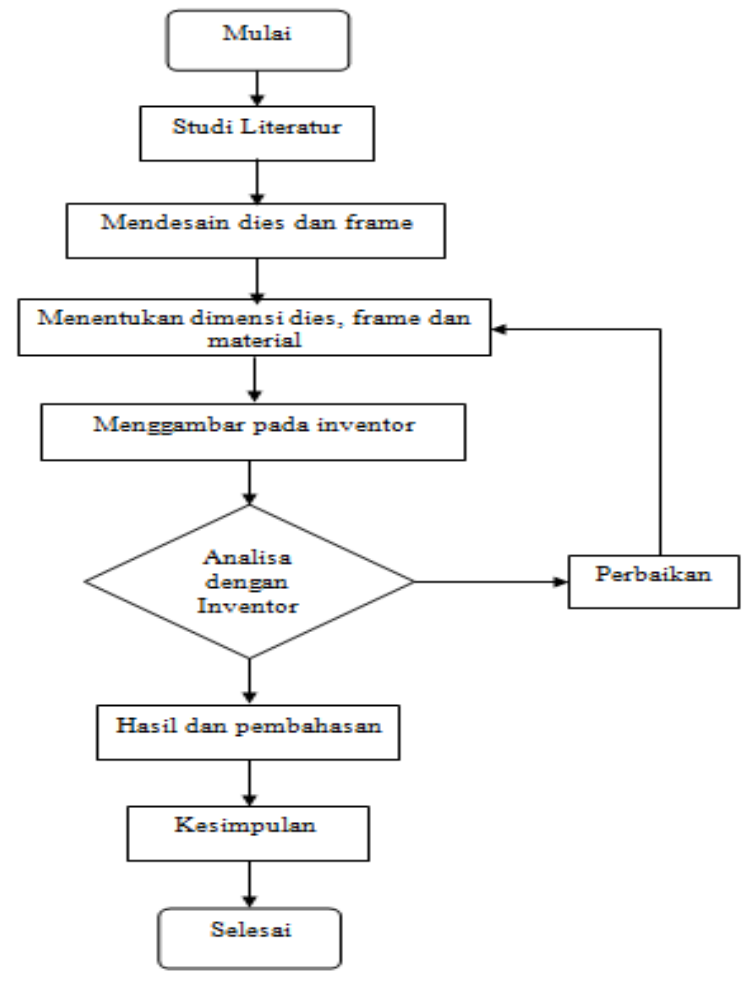

Gambar 4. Flowchart Penelitian

\subsection{Mendesain Dies Dan Frame}

Diameter pipa $=2$ in, out diameter $\mathrm{OD}=23 / 8$ in, wall thickness $0.218-0.344$ in. Dies berjumlah dua yaitu dies utama dan dies sekunder keduanya dihubungkan dengan frame atas dan frame bawah, pada ujung frame dekat dies sekunder dihubungkan dengan aktuator hidrolik sebagai sumber gaya penekan pipa. Perhitungan tegangan menggunakan hukum hooke seperti ditunjukkan pada persamaan 1.

$\sigma=\varepsilon . E$

Dimana : $\sigma$ adalah tegangan, $\varepsilon$ adalah regangan dan $\mathrm{E}=$ modulus elastisitas.

Persamaan tegangan bengkok ditunjukkan pada persamaan 2.

$$
\sigma_{b}=\frac{M b}{W b}
$$

Dimana ; Mb adalah momen bengkok, $\mathrm{Wb}$ adalah momen tahanan bengkok.

Momen tahanan bengkok poros berlubang/pipa $\left(\mathrm{W}_{\mathrm{b}}\right)$ dapat dihitung dengan persamaan 3 .

$W_{b}=\frac{\pi}{32}\left(\frac{d_{0}{ }^{4}-d_{1}{ }^{4}}{d_{0}}\right)$

Dimana; do adalah diameter luar, di adalah diameter dalam 
Diperoleh hasil dari perhitungan dengan persamaan 3 besarnya tegangan bengkok pada frame adalah 2130,525 $\mathrm{N} / \mathrm{mm}^{2}$

Gaya pembengkokan pipa $(\mathrm{Fb})$ dapat dihitung dengan persamaan 4.

$F b=f t . \pi \cdot d \cdot t$

Dimana ; ft adalah tegangan Tarik, d adalah diameter dalam pipa (mm), t adalah tebal pipa (mm)

Persamaan gerak dinamis aktuator hidrolik pada saat proses pengerolan ditunjukkan oleh persamaan 5 [8].

$M \cdot a=-P_{1} A_{1}+P_{2} A_{2}-M \cdot g+F_{f}+F_{b}-B \cdot \dot{X}-\dot{k} \cdot X$

Dimana : M adalah massa beban, a adalah percepatan, $\mathrm{P}$ adalah tekanan fluida, A adalah luas torak, $\mathrm{g}$ adalah gravitasi, $\mathrm{F}_{f}$ adalah gaya gesek pada aktuator dan $\mathrm{F}_{\mathrm{b}}$ adalah gaya pembengkokan pipa.

\subsection{Menentukan Dimensi Dies Dan Frame}

Diameter dies utama $=$ diameter luar pipa $\times 5$, tebal dies $=80 \mathrm{~mm}$, R dies $=25 \mathrm{~mm}$, material $=$ iron cast Diameter dies sekunder $=$ diameter luar pipa $\times 3$, tebal dies $=80 \mathrm{~mm}, \mathrm{R}$ dies $=25 \mathrm{~mm}$, material $=$ iron cast Panjang frame $=475 \mathrm{~mm}$, lebar frame $=50 \mathrm{~mm}$, tebal frame $=15 \mathrm{~mm}$, material $=$ iron cast, lubang pada frame 30 $\mathrm{mm}$. Momen inersia batang segi empat dapat dihitung dengan persamaan 6 dan 7 .

$I_{x}=\frac{1}{12} \cdot b \cdot h^{3}$

$I_{y}=\frac{1}{12} \cdot h \cdot b^{3}$

Momen inersia lingkaran dapat dihitung berdasarkan persamaan 8.

$I_{o}=\frac{\pi}{32} \cdot d^{4}$

Dimana; $\mathrm{b}$ adalah lebar, $\mathrm{h}$ adalah tinggi, dan d adalah diamater

Diperoleh hasil dari perhitungan dengan rumus besarnya momen inersia pada frame adalah $451.258 .831,1 \mathrm{~mm}^{4}$

Defleksi pada frame dapat dihitung berdasarkan persamaan 9.

$\delta=\frac{P . L^{3}}{3 . E . I}$

Diperoleh hasil dari perhitungan dengan rumus besarnya defleksi pada frame adalah 0,0435 mm

Tegangan Von misses dapat dihitung dengan persamaan 10 dan 11.

$$
\tau \boldsymbol{g}=\frac{V}{A}
$$

$\sigma_{\max }=\frac{\sigma x-\sigma y}{2}+\sqrt{\left(\frac{\sigma x-\sigma y}{2}\right)^{2}+(\tau x y)^{2}}$

Diperoleh hasil dari perhitungan dengan rumus besarnya Von mises pada frame adalah 2130,528 N/mm²

\subsection{Menggambar Pada Inventor}

Desain dies mesin rol pipa ditunjukkan pada gambar 5. 


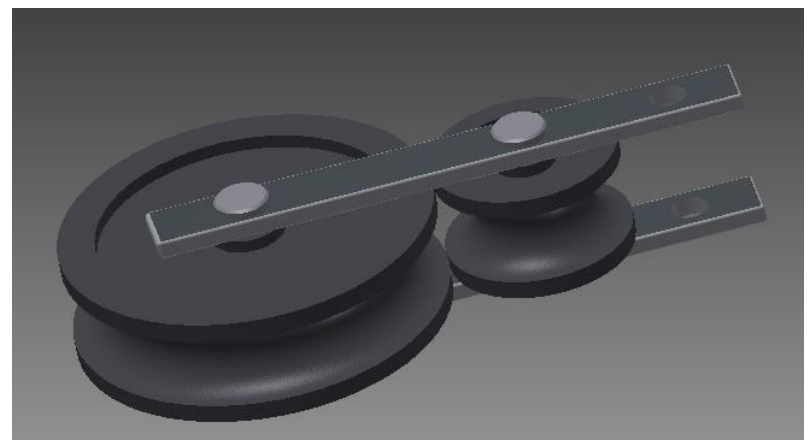

Gambar 5. Dies Mesin Roll Pipa

Desain dari dies mesin roll pipa terdiri dari dies utama yaitu dies yang besar, dies sekunder yaitu dies yang kecil dan frame sebagai penghubung kedua dies dengan aktuator hidrolik sebagai sumber gaya membengkokkan pipa. Dimensi dies mesin roll pipa, diameter dies utama $=300 \mathrm{~mm}$, diameter dies sekunder $=150 \mathrm{~mm}$, Tebal dies $=80$ $\mathrm{mm}, \mathrm{R}$ dies $=25 \mathrm{~mm}$, material $=$ iron cast, panjang frame $=475 \mathrm{~mm}$, lebar frame $=50 \mathrm{~mm}$, tebal frame $=15 \mathrm{~mm}$

\subsection{Menganalisa dengan Metode Elemen Hingga}

Frame diberi beban $220 \mathrm{kN}$ pada bagian yang dekat dengan kontak pipa, pada bagian ini mengalami pembebanan yang paling besar. Bagian dies utama dan dies sekunder yang mengalami kontak dengan pipa juga mendapat gaya yang besar.

\section{HASIL DAN PEMBAHASAN}

Simulasi pembebanan pada rancangan dies mesin roll pipa dilakukan pada komponen frame saat membengkokkan pipa 2 in dengan gaya $220 \mathrm{kN}$. Bagian dies yang bersentuhan dengan pipa memperoleh pembebanan paling besar ditandai pada area yang berwarna merah.

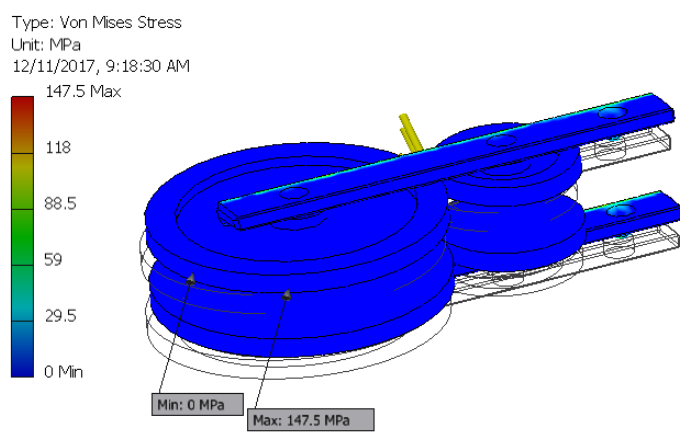

Gambar 6. Von Mises Stress

Pada gambar 6 ditunjukkan hasil analisis dengan metode elemen hingga untuk tegangan von mises. Hasil analisis menunjukkan bahwa tegangan terdistribusi ke semua bagian komponen frame. Tegangan von mises maksimum pada daerah dies yang bersentuhan dengan pipa yang dirol dengan tegangan maksimum 147,5 MPa dan minimum 0 Mpa. Nilai tegangan von mises maksimum ini lebih kecil dari hasil perhitungan $2130,528 \mathrm{MPa}$

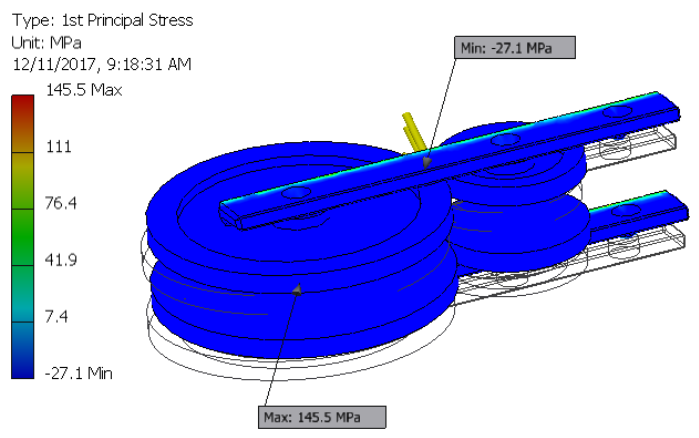

Gambar 7. Principal Stress 
Pada gambar 7 ditunjukkan analisa tegangan principal dengan metode elemen hingga. Tegangan principal maksimum sebesar $145,5 \mathrm{MPa}$ dan tegangan minimum -27,1 MPa. Tegangan principal maksimum lebih kecl dari hasil perhitungan sebesar 2130,525 N/mm² $=2130,525 \mathrm{MPa}$.

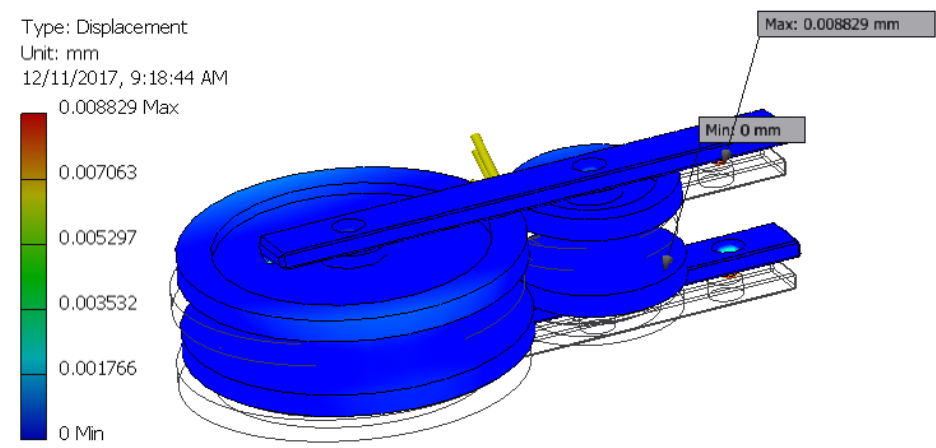

Gambar 8. Displacement

Pada gambar 8 ditunjukkan nilai displacement yang terjadi pada rol pipa. Nilai displacement maksimum sebesar 0,008829 $\mathrm{mm}$ dan minimum $0 \mathrm{~mm}$. Nilai displacement pada frame lebih kecil dari hasil perhitungan 0,045 $\mathrm{mm}$ dari hasil analisis dengan metode elemen hingga. Dengan nilai displacement yang kecil tidak mempengaruhi pergerakan frame dan dies saat proses pengerolan pipa.

\section{KESIMPULAN}

Dari hasil perhitungan, pemodelan dan simulasi dengan metode elemen hingga untuk pengujian kekuatan dies frame link dengan software inventor pada proses pembengkok pipa 2 in diperoleh tegangan principal 145,5 MPa lebih kecil dari perhitungan tegangan bengkok pada frame adalah 2130,525 MPa. Nilai displacement $0,008829 \mathrm{~mm}$ lebih kecil dari perhitungan defleksi pada frame adalah 0,0435 mm., dan nilai tegangan von mises $147,5 \mathrm{MPa}$. Lebih kecil dari perhitungan besarnya Von mises pada frame adalah 2130,528 MPa.

\section{DAFTAR PUSTAKA}

[1] T. A. Wibowo, W. P. Raharjo, and B. Kusharjanta, "MESIN TEKUK PLAT HIDROLIK Keywords: Abstract:", vol. 12, pp. 63-70, 2014.

[2] A. M. P. Divyesh D. Panchal, "Experimental Investigations in Pipe Bending Methods: A Literature Review," Int. J. Adv. Res., vol. 4, no. 4, pp. 144-149, 2016.

[3] T. V Rohit, P. S. Ashutosh, K. V Shriraj, P. P. Akash, and P. G. Shivam, "Design and Fabrication of Pipe Bending and Pipe Rolling Machine,” Int. J. Adv. Res. Ideas Innov. Technol., vol. 3, no. 2, pp. 561-565, 2017.

[4] A. Basti, A. K. Rad, and S. R. Motallebi, "Optimized Design of Cold Roll Forming Process for Production of Rectangular Pipe based on the Taguchi and Finite Element Method," pp. 3-8, 2011.

[5] A. V Kale and H. T. Thorat, "Control of Ovality in Pipe Bending: a New Approach," no. Aimtdr, pp. 1-5, 2014.

[6] Y. Hermawan and S. Purwadi, "Peningkatan Kualitas Produk UKM Kursi Lipat Dengan Metode Internal Pressure dan Rancang Bangun Mesin Bending Konvensional," vol. penelitian, pp. 1-12, 2013.

[7] Badriyana, "Analisis tegangan pada bengkokan pipa dalam sistem pemipaan fasilitas nuklir dengan metode elemen hingga," pp. 111-118, 2005.

[8] M. Kabib, I. M. L. Batan, B. Pramujati, and A. S. Pramono, "Analisa Pemodelan dan Simulasi Gerak Aktuator Punch pada Mesin Pres untuk proses Deep Drawing,” no. Snttm Xiv, pp. 7-8, 2015. 